\title{
A HISTÓRIA DA ARTE BRANCO-BRASILEIRA E OS LIMITES DA HUMANIDADE NEGRA
}

THE HISTORY OF WHITE-BRAZILIAN ART AND THE LIMITS OF BLACK HUMANITY

\section{Kleber Antonio de Oliveira Amancio}

CECULT/UFRB

Resumo: Esse artigo visa apresentar o conceito de história da arte branco-brasileira a partir de uma leitura crítica da tradição erigida por uma literatura da arte epistemologicamente eurocentrada. A partir desse diagnóstico pretendemos apontar caminhos para a construção de um ambiente democratico e afeito a incorporação das narrativas por muito obliteradas pelo projeto colonial.

Palavras-Chave: arte afro-brasileira, história da arte, branquitude.

Abstract: This article aims to present the concept of white-Brazilian art history from a critical reading of the tradition erected by an epistemologically Eurocentric art literature. Based on this diagnosis, we intend to point out paths for the construction of a democratic environment to incorporate narratives that were obliterated by the colonial project.

Keywords: afro-brazilian art, art history, whiteness 
História é fruto do poder, mas o poder por si só nunca é tão transparente que sua análise se torne desnecessária. A marca última do poder pode ser a invisibilidade; o desafio derradeiro, a exposição de suas raízes [tradução nossa]. Michel-Rolph Trouillot

O fato é que a civilização chamada "europeia", a civilização "ocidental", tal como foi moldada por dois séculos de regime burguês, é incapaz de resolver os seus dois principais problemas que sua existência originou: o problema do proletariado e o problema colonial. Esta Europa, citada ante o tribunal da "razão" e ante o tribunal da "consciência", não pode justificar-se; e se refugia cada vez mais em uma hipocrisia ainda mais odiosa, porque tem cada vez menos probabilidades de enganar. A Europa é indefensável. Aimé Césaire

\section{Sobre a parcialidade da narrativa histórica}

A História tem se constituído, desde o século XIX, como a ciência, ou o ofício, que se ocupa das transformações humanas ao longo do tempo (BLOCH, 1974; LE GOFF, 1988). Mais do que simplesmente investigar o passado, num ritual de curiosidade inócuo, historiadores a formulam a partir das demandas de seu tempo; mediante a presença de fontes elaboramos textos que dão conta de racionalizar acontecimentos, porvezes desconexos, numa narrativa verossímil e inteligível à nossa sensibilidade (GINZBURG, 1991). É um saber essencialmente parcial e transitório que se esgota à medida que os litígios, que envolvem a realidade temporal a qual pertencem, arrefecem.

Ao produzir História dissertamos, necessariamente, sobre uma terra estrangeira. $O$ interesse por outro tempo, por outras estórias, delineiase a partir de uma reflexão crítica do campo, mas também de sua relação com o presente
(HALL, 2006). O passado é agora. Ao menos aquele que se tornou historicamente relevante para os sujeitos que sobre ele escrevem; "as ruínas de escombros que crescem até o céu” evidenciam que não somos uma folha em branco. Reconstruir a casa de Matacavalos não fará com que nossa fisionomia remoce, mas colocará em discussão as mudanças, inquietações diante de ausências, permanências, exposições e silêncios de um processo [sempre] em curso.

Como toda forma de produção de conhecimento a História é "fruto do poder". Aqueles que a escrevem o fazem de um locus - que na pós-modernidade ao menos é informado, dentre outras cousas, por conceitos que organizam nossas respectivas subjetividades (DAVIS, 2017; GROSFOEGEL \& BERNARDINO-COSTA, 2016). A negação dessas condicionantes, seja sob o verniz da objetividade ou da erudição, expõe o desejo de representação narcísica do mundo (WHITE, 1973; SAID, 1978).

Há quem leia a História da Arte como um campo de estudos autônomo e tributário das tradições principiadas por Vasari e Winckelmann (BAROLSKY, 2010; POTTS, 1994), outros ainda apontam para como as filosofias da arte de Kant e Hegel influenciaram decisivamente os pais fundadores da História da Arte moderna (HOLLY, 1984; CHEETHAM, 2001); de qualquer modo parece seguro afirmar que as diretrizes dessa disciplina foram sistematizadas entre a segunda metade do século XIX e o início do século seguinte. Dvořák, Burckhardt e tantos outros, guardadas as suas particularidades, sintetizaram modos de pensar a História dos objetos de arte a partir do olhar.

A História da Arte propõe-se a teorizar a evolução dos objetos de arte ao longo do tempo, seja em sua relação com a sociedade (WARBURG, 2015; PANOFSKY, 2009; SCHAPIRO, 2010; CLARK, 2004) ou por meio de uma conversa 
ensimesmada, alheada do mundo e voltada às transformações formais (FIEDLER, 2001; WÖLFFLIN, 2006; GOMBRICH, 2013; RIEGL, 2004). Atualmente o campo se vê às voltas com uma reestruturação contínua e acalorada que se faz pelas práticas artísticas e curatoriais contemporâneas, pelo diálogo com outras disciplinas (CARDOSO, 2009; CLARK, 2007) ou ainda pela emergência de novas teorias da arte gestadas a partir da emergência de um pensamento de fronteira (MUKHERJI, 2014).

Se examinamos, por exemplo, o livro "História da Arte" de Ernest Gombrich notamos que se trata de um grande elogio à arte europeia (GOMBRICH, 2013). Ao longo dos vinte e oito capítulos que compõem o volume em apenas três a temática não está relacionada à Europa. ${ }^{1}$ Diante disso ou cremos que toda a qualidade artística "universal" esteve concentrada no gênio de seletos artistas que por acaso, ou providência divina, nasceram em alguns poucos países do velho continente, ou questionamos as maneiras como esses cânones foram egoicamente construídos (RANKIN, 1995; ÇEYLIK, 2000).

Não se trata, porém, apenas de visibilidade. Em outros momentos construiu-se uma narrativa sobre o "outro" na qual objetos produzidos para determinadas práticas sociais foram impetuosamente descontextualizados e transmutados em "arte", em letras minúsculas (MUDIMBE, 1998). Quanto mais seguiu nessa direção o silenciamento sistêmico-epistemológico da História da Arte só fez revelar sua intrínseca relação genética com o colonialismo (SAID, 1978). Ao definir uma narrativa para esses objetos a partir de seu umbigo, promoveu uma história

1 Os capítulos são "Strange Beginnings" em que trata sobre Arte pré-histórica, povos "primitivos" e América Antiga; "Art for Eternity”, no qual disserta sobre Egito, Mesopotâmia e Creta; e "Looking Eastwards" em que aborda o Islam e a China do século II ao XIII. autocentrada e que apenas recentemente têm sua suposta neutralidade questionada (BENJAMIN, 2003; MARTINEAU \& RITSKES, 2014; COSTA, 2018).

\section{A história da arte branco-brasileira}

A História da Arte Brasileira é branca. É preciso dizê-lo. O cânone histórico foi construído por uma sucessão de narrativas em que a sobressalência de artistas [brancos] é o grande fio condutor. Da "Missão Artística Francesa" de 1816 ao neoconcretismo, passando pelo modernismo [paulista] da semana de 1922 (AMARAL 1998;PEDROSA, 1998; SCHWARCZ, 2008; SQUEFF, 2006; ROSA, 2007). Ao mesmo tempo as epistemologias eurocentradas, largamente utilizadas na construção dessas mitologias, costumeiramente tem se furtado a reconhecer complexidade nas produção de artistas [negros], seja pelo silenciamento ou pela criação de categorias de análises outras em que o efeito colateral inerente seja a subalternização do objeto investigado (CHRISTO, 2009; BITTENCOURT, 2015; CARDOSO, 2015; AMANCIO, 2016; LOTIERZO, 2017)

Agimos, todos, dentro das possibilidades históricas de nosso tempo; somos orientados por um acordo coletivo de caráter sociocultural que serve de matéria prima para as produções humanas. A arte não é uma atividade mágica que pode escapar da implacabilidade do tempo. No mundo que se forjou a partir da experiência colonial o lugar da branquitude é por excelência neutro e universal, é dotado de humanidade (FANON, 1952).

Os (poucos) artistas não-brancos que se encontram no cânone ocupam lugares que lhe são permitidos, um sistema em que são exceção ou apêndice. Como se trata de uma narrativa ficcional que se baseia numa visão de mundo seccionada, frequentemente não condiz com as projeções que fazem de si (AMANCIO, 2016). 
São tidos e havidos como sujeitos transparentes (SPIVAK, 2010). Qualquer tentativa de escapar a essa expectativa é sumariamente silenciada. Nas representações que esse "outro", subalterno, faz de si eventualmente encontramos fissuras que evidenciam a sistematização desse processo capitaneado por uma comunidade que se irmana a partir de uma constituição racial - constróem seu interlocutor simbolicamente, e a si por meio de um sistema de privilégios (SCHUCMAN, 2014). Ao obliterar esse debate a História da Arte se alinhou, inescapavelmente, a um projeto epistêmico colonial. É a História da Arte branco-brasileira.

\section{Fundamentos para uma arte "negra"}

A exclusividade da branqutiude no canône da Arte brasileira está intimamente ligada à elaboração de teorias da arte que dêem conta de categorizar as obras produzidas por artistas negros a partir do processo de subalternização. Essa divisão aposta na peculiaridade de suas produções e na necessidade de se criar um aparato teórico epistemológico particular. Em artigo de 1904, por exemplo, Nina Rodrigues trata das esculturas dos "colonos pretos" no Brasil (RODRIGUES, 1904). Em linhas gerais seu texto argumenta que a arte dos escravizados, a "arte negra”, era de altíssima qualidade uma vez que refletia o fato do país contar com "os povos africanos mais avançados em cultura e civilização”. Dessa maneira propõe que uma vez que não se transponha as regras impostas ao fazer artístico [branco], que em sua concepção encontrava-se num estágio intelectual mais avançado, seria possível perceber relevância e apuro nessa espécie de manifestação artística. ${ }^{2}$

2 É o mesmo ímpeto que, guardadas as devidas proporções, veremos mais tarde em Mariano Carneiro da Cunha. Em texto de 64 anos depois o autor argumenta que "uma arte só faz sentido na medida em que exprima padrões culturais,
Rodrigues entende que é na escultura que os negros desenvolveram com maior apuro suas capacidades. Segundo o autor: "Os sentimentos, as crenças religiosas, fazem para os Negros, como para as outras raças, as despesas das manifestações primitivas da cultura artística". Toda a explicação passa por encaixar o entendimento que os grupos envolvidos tinham da religião a fim de acertar o uso ritual das peças e por conseguinte sua significação cultural. Rodrigues fala em transposição e sobrevivência ao sugerir que essas práticas atravessaram o Atlântico. ${ }^{3}$

O autor ainda aponta as peculiaridades das artes produzidas pelos negros. Pensa as peças a partir da coletividade. Cerca de meio século depois Arthur Ramos vai se enveredar por um caminho parecido (RAMOS, 1949). O etnógrafo alagoano, contudo, passa a estudar não apenas obras produzidas no contexto religioso, mas também daqueles autores chamados primitivos. Devemos nos atentar para o fato de que se hoje as fronteiras entre erudito e popular parecem borradas, por muito tempo o entendimento geral era de que os artistas populares, os naive, produziam a partir de outro paradigma, que, decididamente não era o da racionalidade.

Mariano Carneiro da Cunha, por seu turno, retoma Rodrigues; faz uma detalhada exegese a respeito daquilo que chega a denominar de "arte afro-brasileira". Segundo o autor:

Arte afro-brasileira é uma expressão convencionada artística que, ou desempenha função no culto dos orixás. ou trata de tema ligado ao culto. Esta maneira de definir o campo,

ofereça uma visão de mundo e as ideias que a acompanham. Vide Cunha Marianno Carneiro da. Esboço histórico: o elemento negro nas artes plásticas. In: ZANINI, Walter (org.). História Geral da Arte no Brasil. São Paulo: Instituto Moreira Salles, 1983. p.989-1017.

3 Rodrigues sugere inclusive que a eventual "tosquice" das peças sejam causadas pela interrupção de um sistema de apuração da qualidade artística no novo mundo. 


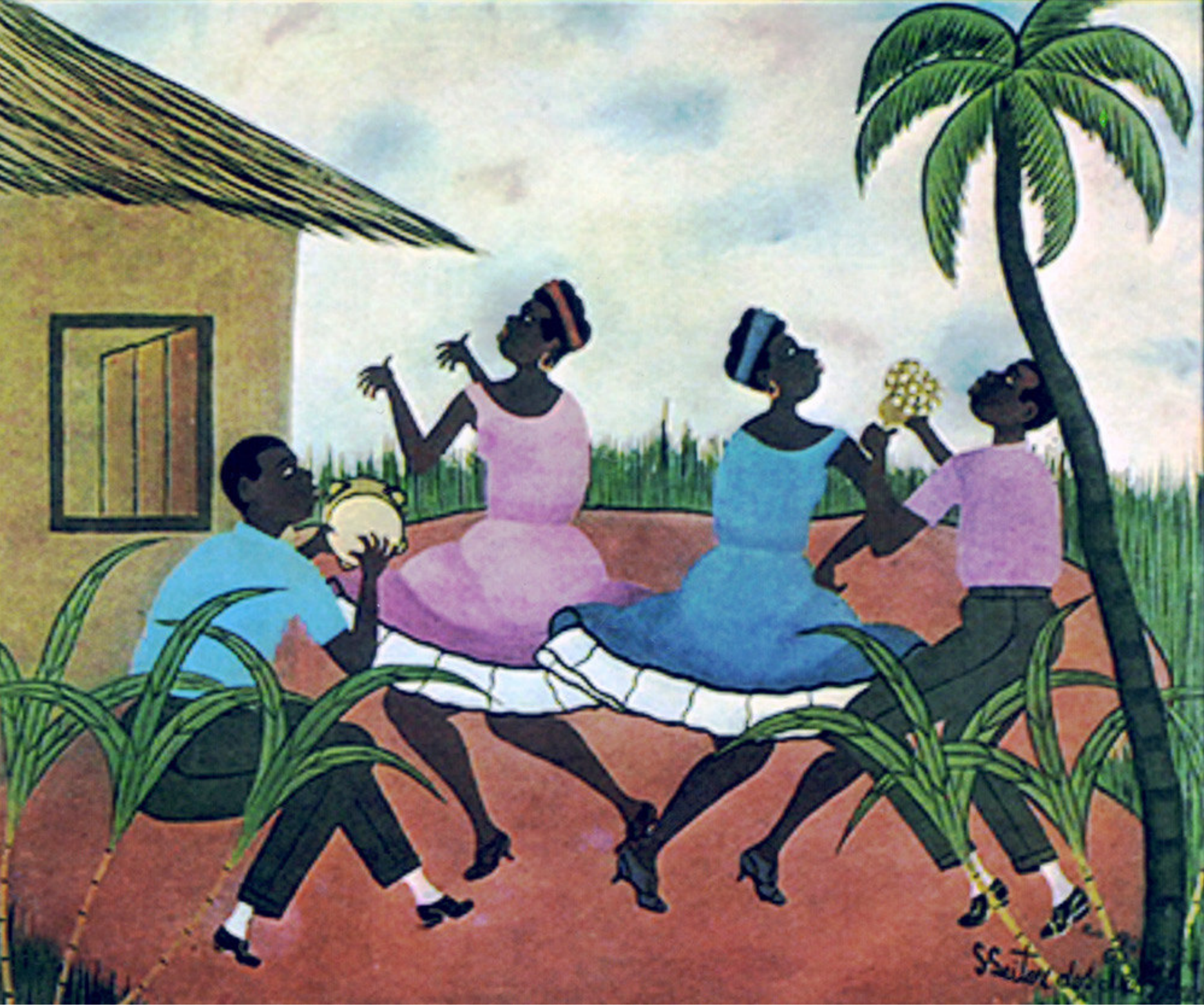

ligando-o a religiões vivas que apelam para uma ascendência africana, traz aparentes anomalias. ligadas precisamente a vitalidade e, portanto, a apropriação de símbolos novos por essas religiões (CUNHA, 1983).

Contudo, diferentemente de Rodrigues, Cunha alarga o conceito de arte afro-brasileira; cria quatro categorias explicativas dentre as quais a obra de artisas brancos que pensam a partir de "temas negros" (CUNHA, 1983). Nessa Figura 1. Emiliano Di leitura, portanto, Tarsila do Amaral, Di Cavalcanti e Portinari teriam produzido "arte afro-brasi1925. Óleo sobre tela. $177 \times 154 \mathrm{~cm}$. leira".

Outro crítico afeito ao tema, Clarival do Prado Valladares, está no epicentro de um episódio suigeneris. Em 1966 foi o responsável por eleger três artistas para compor a delegação brasileira no primeiro encontro Mundial de Artes Negras em Dakar (SALUM, 2000). Àquela oportunidade, 
Figura 2. Heitor dos Prazeres. Samba no Terreiro. 1957. Óleo sobre tela. 55 x $65 \mathrm{~cm}$. Coleção Particular. Reprodução Fotográfica: Pedro Oswaldo Cruz. Disponível em: SAMBA no Terreiro. In: ENCICLOPÉDIA Itaú Cultural de Arte e Cultura Brasileiras. São Paulo: Itaú Cultural, 2021. Disponível em: <http://enciclopedia.itaucultural. org.br/obra4659/ samba-no-terreiro>. Acesso em: 22 de Jun. 2021. Verbete da Enciclopédia. ISBN: 978-85-7979-060-7

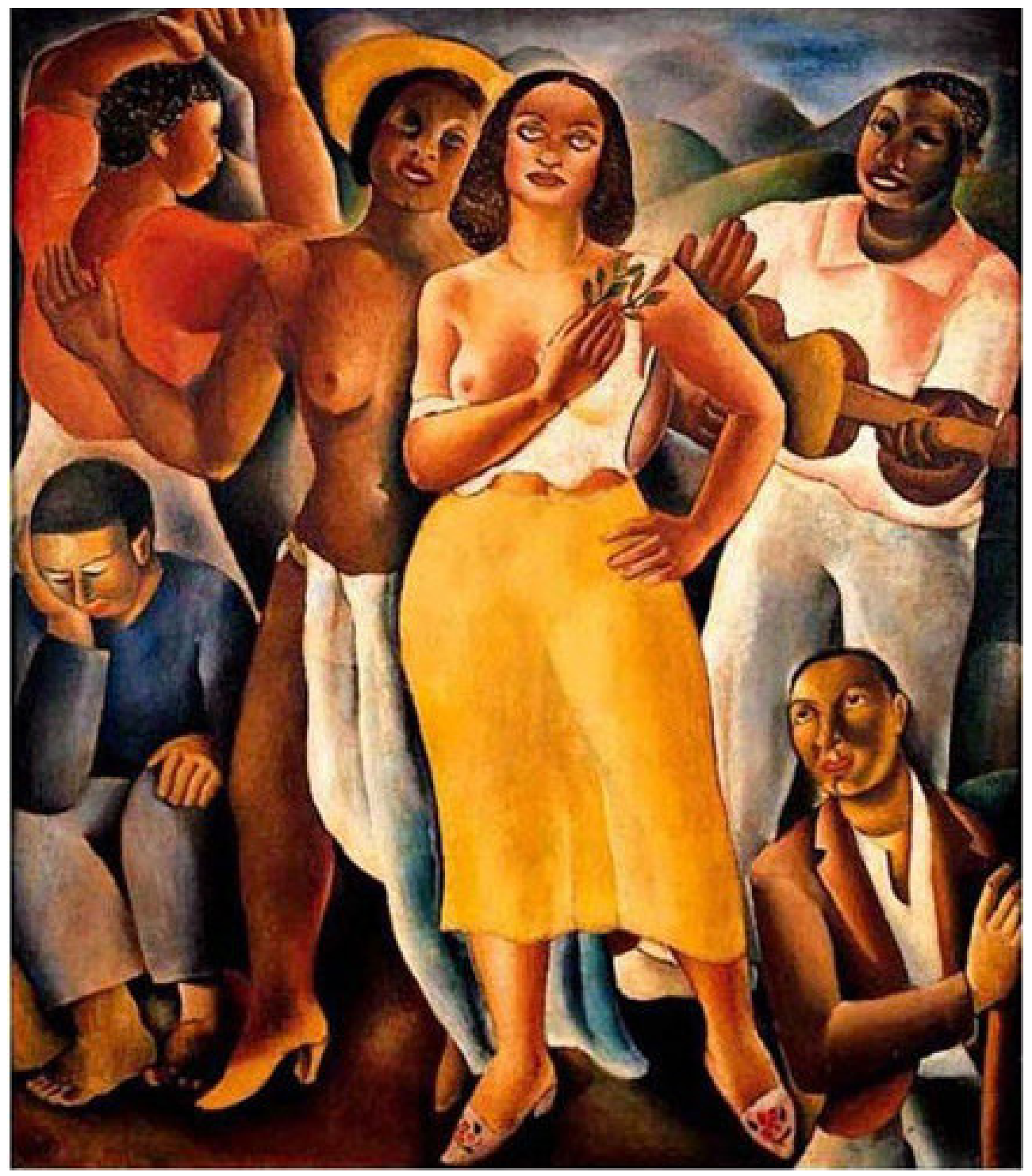

cada país africano ou do mundo diasporico foi convidado para enviar seus representantes. Valladares escolheu três artistas visuais, todos autodidatas. Rubem Valentim, Agnaldo Manoel dos Santos e Heitor dos Prazeres.

A indicação de uma comissão deveras diminuta causou a ira de Abdias do Nascimento que acabou por escrever uma carta que expressasse não apenas sua indignação pelo Teatro Experimental do Negro não ter sido um dos escolhidos, mas porque cria que perdiamos uma grande oportunidade de mostrar a diversidade e a potência do que os artistas negros produziam no país àquela altura.

Mas quem eram esses artistas? Segundo Valladares, Agnaldo Manoel dos Santos era um "Primi- 
tivo". No seu entender: "Sua obra, portanto, merece ser vista em seu caráter de exceção, tanto em relação ao meio como ao tempo em que foi feita. Este caráter de exceção com que distingo a obra de Agnaldo é a ancestralidade que ele vivenciou." (VALLADARES, 1983; 36).

Rubem Valentim, grosso modo, apresentava um diálogo com o construtivismo. Suas peças, mais do que representar, apresentam-se como constructos. Entretanto rejeita um formalismo epistemologicamente branco para buscar um diálogo pensado a partir das referências simbólicas de uma religiosidade afro-brasileira.

Heitor dos Prazeres busca uma representação figurativa das classes populares que aparece em total desacordo com os ditos modernistas (Figura 1). Se em Di Cavalcanti, por exemplo, temos um processo de sexualização dos corpos negros femininos (Figura 2), aqui é recorrente a ideia de ordem, limpeza e dignidade, as personagens, embora sejam apresentadas simbolicamente como tipos, exercem sua individualidade, estão sempre vestidas com as suas melhores roupas e frequentemente calçadas. Diferentemente do que acontece em Portinari, Gustavo Dall'ara e tantos outros, aqui os corpos, na maior parte das vezes, não são representados durante o trabalho, mas quando o são não se percebe a mesma melancolia tão comum em Antonio Ferrigno, Modesto Brocos e Armando Vianna.

Para além da cor da pele, aqueles artistas dialogavam de um determinado lugar, um lugar que era permitido, ainda que de maneira negociada. A despeito de suas obras e trajetórias estarem hoje sendo revistas e reposicionadas a partir da decolonização, àquela altura eram classificados de outra maneira. Não foi o caso, por exemplo, de Wilson de Azevedo Sérgio, um artista que se insurgiu contra esse sistema.

\section{Wilson de Azevedo Sérgio e os limites da hu- manidade (?) negra}

$\mathrm{Na}$ carta de Abdias do Nascimento, que mencionei a pouco aparece a seguinte citação:

Alguns como o poeta Solano Trindade, o maestro Abigail Moura, e os pintores Cleo e Wilson de Azevedo Sérgio, condenaram pelos jornais a forma arbitrária das escolhas. Esqueceram-se, aqueles negros reivindicadores, que os juízes itamaratianos de arte negra são infalíveis, onipotentes e irreversíveis em seu julgamento culturais. Negro não fala. Não protesta. Aceita cabisbaixo o fato consumado. Já não é uma felicidade para ele andar solto por aí, com direito a fazer seu samba e jogo de bola? (NASCIMENTO, 1966)

Pois bem. Quem viriam a ser os dois pintores mencionados por Abdias? Particularmente não os conhecia antes do início da pesquisa e logo descobri que não foi sem razão. Não há qualquer linha sobre os dois na historiografia nacional, contudo pude rastrear a vida de um deles nos jornais. A primeira notícia que tenho do nome de Wilson de Azevedo sendo mencionado numa publicação foi no dia de 1946. A notícia dá conta de um desentendimento que aconteceu por conta de um balão e Wilson de Azevedo Sérgio, é mencionado como tendo levado uma facada na perna. Segundo a matéria contava com 22 anos e era desenhista. 4

Em 1954 seu nome aparece como um dos que compareceram a uma versissage no Museu de Arte Moderna do Rio de Janeiro a respeito de uma exposição cubista.5 Em 1956 vemos uma nota em que há um detalhamento de sua carreira. Segundo esta, o artista é do estado do Rio de Janeiro, mas mora na capital desde os 2 anos de idade. Fez curso secundário e em seguida

4 A noite. Rio, 24 de junho de 1946, p. 2.

5 Correio da Manhã, 17 de março de 1954, p.10. 
Figura 3. Correio da Manhã, 20 de janeiro de 1956, p.8

Figura 4. Correio da Manhã, 12 de janeiro de 1958, p.11

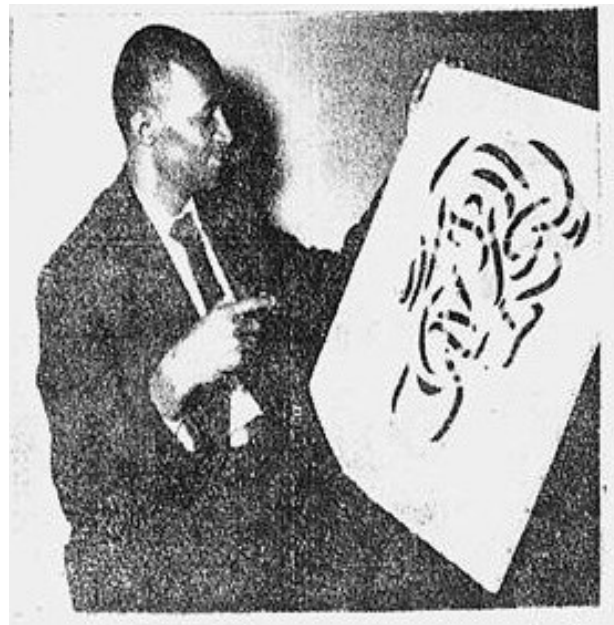

frequentou o curso Oberg. Trabalhou nos escritórios das seguintes personalidades: Oscar Niemeryer, Henrique Mindlin e Sérgio Bernardes. É desenhista desde os 11 anos. Na ocasião havia criado uma máscara (Figura 3). Interessante ainda notar que a matéria comenta que ele têm o interesse em participar da quarta bienal de São Paulo.6

Nos dias 12 e 20 de janeiro de 1958 temos duas notas muito parecidas que dizem o seguinte.

WILSON DE AZEVEDO SÉRGIO - Que com sucesso expôs no IV Salão Paulista de Arte Moderna, e que tem já a sua posição firmada na arte figurativa, está se preparando para o envio de quadros à uma exposição que será dentro em breve realizada no México. O conhecido pintor, patrício fará, no carnaval que se aproxima, as suas telas aproveitadas para a ornamentação da cidade, pelo Departamento de Turismo, e também, o América F. C, fará decorar, os seus salões por ocasião dos festejos do Momo.?

Como podemos notar Wilson de Azevedo Sérgio, ao que tudo indica, possuía uma carreira promissora. Estava envolvido na realização de

6 Correio da Manhã, 20 de janeiro de 1956, p.8 7 Imprensa Popular. Rio, 17 de janeiro de 1958, p.6.

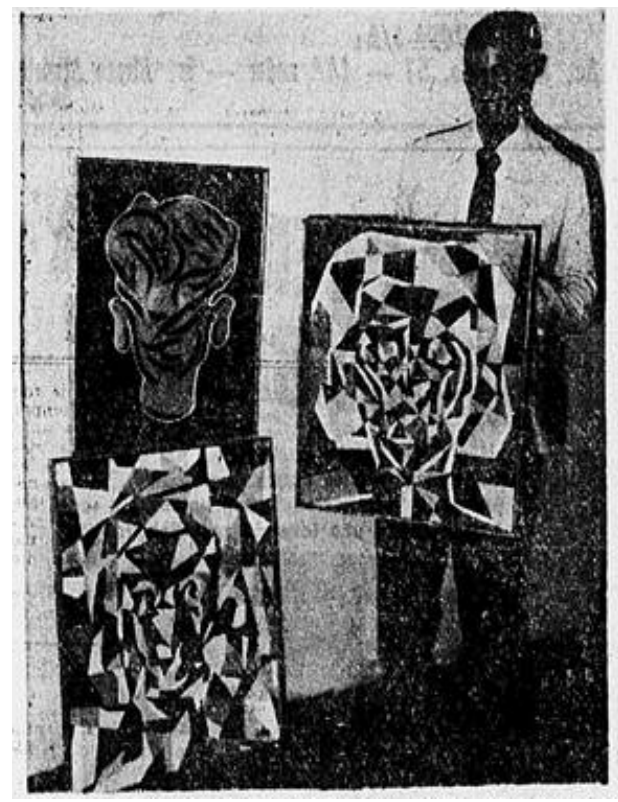

uma exposição internacional, além de trabalhar para o Estado como artista contratado. Mas do que tratariam suas obras? Nas duas fotos dessa época que pudemos encontrar possível notar que uma mesma retórica se repete. O corpo do artista colado às suas criações. Na segunda fotografia, sobremaneira, nota-se que produzia pinturas abstratas (Figura 4). Ao menos num primeiro olhar, num espírito muito diferente daqueles artistas que analisamos há pouco.

Em 1966, quando da indicação dos já mencionados artistas para participar de Dakar, encontramos uma notícia de que Wilson de Azevedo Sérgio estava a organizar um protesto com artistas negros contra o diminuto número de artistas. Durante a matéria ele detalha ainda algo bastante interessante. Segundo o artista:

- Não quero dizer que Heitor dos Prazeres seja um mau pintor - explicou Wilson Sérgio sua pintura até que é boa e possui grande pesquisa. Mas é primitivista e não transmite uma mensagem atual, pois a pintura evoluiu bastante nos últimos tempos. O Sr. Wilson Sérgio é de opinião de que deveria ser dada uma oportunidade aos 
artistas bons e desconhecidos internacionalmente, ao contrário do critério adotado pelo Itamarati, "porque precisa ser mostrar do que o Brasil progrediu nos últimos tempos também na pintura. ${ }^{8}$

A passagem é complexa e nos ensina algumas coisas. Primeiramente, Wilson de Azevedo Sérgio entendia que estava no meio de uma disputa política pelo sentido da arte negra no Brasil. Sabia da importância política da exposição, mas, mais do que isso, sabia que enviar artistas "primitivos" para a exposição significava comprar um estereótipo, no seu entender negativo. Interessante pensar que para o desenhista, existe uma arte de vanguarda e uma arte menor, menos atual. Sua fala aposta numa disputa pela possibilidade da criação de uma representação da arte negra que seja apartada da simbologia relacionada à religiosidade afro-brasileira. Lutava pela possibilidade de falar sobre o que quisesse e isso ser considerado arte negra, para além do que teorizavam os hegemônicos trabalhos de Nina Rodrigues, Arthur Ramos e Clarival do Prado Valladares. Ao propor isso, o artista desafiou o paradigma racial brasileiro então vigente, a ordem colonial. Afinal nesse mundo pós-colonial, os únicos que são dotados de humanidade, portanto de escolhas, são os brancos. Quando o sentido da representação da arte negra no Brasil está entre um teórico branco e um grupo de artistas negros, é signo de a branquitude estava a ser enfrentada. Isso gerou consequências pessoais terríveis para a vida de Wilson de Azevedo Sérgio. A próxima notícia é dos anos 1970, longe das exposições passou a vender lâmpadas para sobreviver.9

Se hoje a memória vitoriosa da construção de uma História da Arte Afro-brasileira passa pelos artistas naive e não por casos como o de Wilson

8 Jornal do Brasil, 11 de janeiro de 1966, p. 10.

9 Correio da Manhã, 18 de janeiro de 1971, p. 9; Correio da Manhã, 17 de março de 1971, p.4 de Azevedo Sérgio, devemos repensar a afirmação de Aracy Amaral segundo a qual:

Na realidade, a razão fundamental é sempre a marginalização econômica. Ou seja, o homem de origem humilde, com permanente dificuldade de acesso a uma formação cultural de nível mais ou menos elevado, em país onde o sistema educacional já é, por si só, tão elitista como carente em geral quanto à qualidade. A inexistência de um número maior de artistas plásticos de origem negra é tão real quanto sua ausência das universidades brasileira (AMARAL, 2010).

Me parece absolutamente sintomático que um artista com carreira relativamente bem estabelecida seja silenciado sumariamente por não acordar com um projeto epistemológico imposto aos artistas negros. "Falar é existir absolutamente para o outro", conforme observa Fanon. Precisamos repensar a gênese da narrativa da História da Arte brasileira, seu silencioso e violento processo de normatização da branquitude. Parece-me absolutamente sintomático que durante muito tempo os artistas negros fossem considerados inexistentes; descortirnar essas narrativas é re-fazer a humanidade, avançar no processo de provincialização da Europa; estabelecer um marco civilizatório.

\section{Referências}

AMANCIO, Kleber. Reflexões sobre a pintura de Arthur Timotheo da Costa. 2016. Tese de doutoramento em História Social. São Paulo, FFLCH-USP.

AMARAL, Aracy. Artes plásticas na Semana de 22. 5. ed. São Paulo: Editora 34, 1998.

AMARAL, Aracy. "Um inventário Necessário e Algumas Indagações: a Busca da Forma e da Expressão na Arte Comtemporânea." In ARAÚJO, Emanuel (org.). A mão afro-brasileira. Significado da contribuição artística e histórica. 2. ed. 
revista e ampliada São Paulo: Imprensa Oficial do Estado de São Paulo/ Museu Afro Brasil, 2010. vol.Il. p.10.

BAROLSKY, Paul. A brief history of the artist from God to Picasso. University Park, PA: Pennsylvania State University Press, 2010.

BENJAMIN, Roger. Orientalist Aesthetics: Art, Colonialism, and French North Africa, 18801930. Berkeley: University of California Press, 2003.

BLOCH, March. Introdução à História. Lisboa: Europa-América, 1974.

BITTENCOURT, Renata. Um dândi negro: o retrato de Arthur Timótheo da Costa de Carlos Chambelland. 2015. Tese de doutoramento em História da Arte. Campinas, IFCH-UNICAMP.

CARDOSO, Rafael. "A história da arte e outras histórias". Cultura Visual, n. 12, outubro/2009, Salvador: EDUFBA, p. 105-113.

_. 'The Problem of Race in Brazilian Painting, c. 1850-1920”. Art History. June, 2015.

CHEETHAM, Mark. Kant, Art and Art History: Moments of Discipline. New York, Cambridge University Press, 2001.

CÉSAIRE, Aimé. Discours sur le colonialisme. Reclame, 1950.

ÇEYLIK, Zenep. "Colonialism, Orientalism and the Canon". In BORDEN, lain \& RENDELL, Jane. Intersections: Architectural Histories and Critical Theories. Routledge, London and New York, 2000.

CHIARELLI, Tadeu. "De Anita à academia: para repensar a história da arte no Brasil". Novos estud. - CEBRAP no.88 São Paulo Dec. 2010.

CHRISTO, Maraliz de Castro Vieira. "Algo além do moderno: a mulher negra na pintura brasileira no início do século XX”. 19\&20, Rio de Janeiro, v. IV, n. 2, abr. 2009.

CLARK, T. J. A pintura da vida moderna: Paris na arte de Manet e seus seguidores. São Paulo: Companhia das letras, 2004.
_-_ Modernismos: ensaios sobre política, história e teoria da arte. São Paulo: Cosac \& Naify, 2007.

COSTA, Raquel. "Após o fim da arte europeia: uma análise decolonial do pensamento sobre a produção artística”. Dois pontos. Curitiba, São Carlos, volume 15, número 2, p. 89-98, setembro de 2018.

CUNHA, Marcelo N. Bernardo da; NUNES, Eliene \& SANDES, Juipurema A. Sarraf. "Nina Rodrigues e a Constituição do Campo da História da Arte Negra no Brasil”. Gazeta Médica da Bahia, 2006; 76 (Suplemento 2):23-28.

DAVIS, Angela. Mulheres, raça e classe. São Paulo: Boitempo, 2017.

FANON, Frantz. Peau noire, masques blancs Paris: Éditions du Seuil, 1952.

FIEDLER, Konrad. Escritos sobre Arte. Madrid, Visor, 1991.

GINZBURG, Carlo. Il giudice e lo storico: considerazioni in margine al processo Sofri. Torino: Einaudi, 1991.

GOMBRICH, Ernest. A história da arte. Rio de Janeiro: LTC, 2013.

GONZAGA DUQUE ESTRADA, Luiz. A arte brasileira: pintura e esculptura. Rio de Janeiro: $H$. Lombaerts, 1888.

GROSFOEGEL, Ramon \& BERNARDINO-COSTA, Joaze. Decolonialidade e perspectiva negra. Revista Sociedade e Estado - Volume 31 Número 1 Janeiro/Abril 2016.

HALL, Stuart. A identidade cultural na pósmodernidade. Rio de Janeiro, DP \& A, 2006.

HOLLY, Michael Ann. Panofsky and the foundations of Art History. Ithaca: Cornell University Press, 1984.

LE GOFF, Jacques. História e Memória. $5^{\mathrm{a}}$ Ed. Campinas: Editora da UNICAMP, 2010.

LEITE, José Roberto Teixeira. Dicionário crítico da pintura no Brasil. Rio de Janeiro: Artlivre, 1988. 
LOTIERZO, Tatiana. Contornos do (In)visível: Racismo e Estética na Pintura Brasileira (18501940). São Paulo: EDUSP, 2017.

MARTINEAU, Jarret. \& RITSKES, Eric. "Fugitive indigeneity: Reclaiming the terrain of decolonial struggle through Indigenous art". In: Decolonization: Indigeneity, Education \& Society Vol. 3, No. 1, 2014, pp. I-XII.

NASCIMENTO, Abdias. "Carta a dacar". In: Tempo. Rio de Janeiro-Abril, 1966, pp. 97-106.

NAVES, Rodrigo. A forma difícil: ensaios sobre arte brasileira. Edição revista e ampliada. São Paulo: Companhia das Letras, 2011.

NUNES, Eliene. "Raimundo Nina Rodrigues, Clarival do Prado Valladares e Marianno Carneiro da Cunha: três historiadores da arte afro-brasileira". In CADERNOS DO MAV - EBA - UFBA, pp. 109-122.

PANOFSKY, Erwin. Significado nas artes visuais. São Paulo, Perspectiva, 2009.

PEDROSA, Mário. "Da missão francesa: seus obstáculos políticos” In ARANTES, Otília. (org.) Mario Pedrosa: Acadêmicos e Modernos. Textos Escolhidos III. São Paulo, Edusp, 1998.

POTTS, Alex. Flesh and the ideal: Winckelmann and the origins of art history. New Haven: Yale University Press, 1994.

RAMOS, Arthur. "Arte negra no Brasil". In: Cultura, v. 1, n. 2, Rio de Janeiro: 1949. pp 189-212.

RANKIN, Elizabeth. "Recoding the canon: Towards greater representivity in South African art galleries". Social Dynamics: A journal of African studies. Volume 21, 1995 - Issue 2.

RIEGL, Alois. Historical grammar of the visual arts. New York: Zone Books, 2004.

ROSA, Luisa Günther. Neoconcretismo: manifesto e práxis. 2007. 104 f. Dissertação (Mestrado em Sociologia). Universidade de Brasília, Brasília, 2007.

RUBENS, Carlos. Pequena história das artes plásticas no Brasil. São Paulo: Editora
Nacional, 1941.

SAID, Edward W. Orientalism. New York: Pantheon Books, 1978.

SALUM, Marta Heloísa Leuba. "Cem anos de arte afro-brasileira”. In NEYT, FRANÇOIS; VANDERHAEGHE, Catherine; MUNANGA, Kabengele; SALUM, Marta Heloísa Leuba. Arte afro-brasileira. São Paulo: Associação Brasil 500 Anos Arte Visual: Fundação Bienal de São Paulo, 2000. p.112-121.

SCHAPIRO, Meyer. A arte moderna: séculos XIX e XX: ensaios escolhidos. São Paulo: EDUSP, 2010.

SCHUCMAN, Lia Vainer. Entre o encardido, o branco e o branquíssimo: branquitude, hierarquia e poder na Cidade de São Paulo. São Paulo: Annablume, 2014.

SCHWARCZ, Lilia. 0 sol do Brasil: Nicolas-Antoine Taunay e as desventuras dos artistas franceses na corte de d. João. São Paulo: Companhia das Letras, 2008.

SQUEFF, Letícia. Revendo a Missão Francesa: A missão artística de 1816, de Afonso D'escragnolle Taunay. Anais do Encontro de História da Arte da UNICAMP, 2006.

SPIVAK, Gayatri. Pode o subalterno falar?. Belo Horizonte: Editora UFMG, 2010.

TROUILLOT, Michel-Rolph. Silencing the Past: Power and the Production of History. Boston: Beacon Press, 1995.

VALLADARES, Clarival do Prado. Paisagem rediviva. Salvador: Imprensa Oficial da Bahia, 1962.

"Agnaldo Manoel dos Santos: Origem e Revelação de um escultor primitivo". In Afro-Ásia, 14, 1983.

VERMEERSCH, Paula. 2012. 268fls. Notas de um estudo critico sobre A Arte Brasileira, de Luiz Gonzaga Duque Estrada. Dissertação de Mestrado em História da Arte. Campinas, IFCH -UNICAMP. 
WARBURG, Aby. Histórias de fantasma para

gente grande: escritos, esboços e conferências.

São Paulo, Companhia das Letras, 2015.

WHITE, Hayden. Metahistory: the historical imagination in nineteenth century Europe. Baltimore: Johns Hopkins University Press, 1973.

WÖLFFLIN, Heinrich. Conceitos fundamen-

tais da história da arte: o problema da evolução dos estilos na arte mais recente. São Paulo: Martins Fontes, 2006.

MUKHERJI, Parul Dave. Whither Art History: Whither Art History in a Globalizing World. The Art Bulletin Vol. 96, No. 2 (June 2014), pp. 151155.

ZANINI, Walter. História Geral da Arte No

Brasil. São Paulo : Instituto Walther Moreira Salles : Fundação Djalma Guimarães, 1983. 2 vol.

\section{Kleber Antonio de Oliveira Amancio}

Possui graduação, bacharelado e licenciatura, em História pela Universidade Estadual de Campinas (2006), mestrado em História Social pela Universidade de São Paulo (2010) e doutorado em História Social pela Universidade de São Paulo (2016). Foi pesquisador visitante na Harvard University (2014-2015). A principal área de pesquisa é História do Brasil nos séculos XIX e XX, com publicações em temas tais como história de Campinas, do Rio de Janeiro, da escravidão, da abolição, do pós-abolição, da literatura e da arte. Atualmente é coordenador do Bacharelado Interdisciplinar em Cultura, Linguagem e Tecnologias Aplicas da Universidade Federal do Recôncavo da Bahia. 